\title{
Current Research on Methamphetamine-Induced Neurotoxicity: Animal Models of Monoamine Disruption
}

\author{
Taizo Kita ${ }^{1,2}$, George C. Wagner ${ }^{3}$, and Toshikatsu Nakashima ${ }^{1, *}$ \\ ${ }^{1}$ Department of Pharmacology, Nara Medical University, 840 Shijo-cho, Kashihara, Nara 634-8521 \\ ${ }^{2}$ Department of Pharmacology, Daiichi College of Pharmaceutical Sciences, \\ 22-1 Tamagawacho, Minamiku, Fukuoka 815-8511, Japan \\ ${ }^{3}$ Department of Psychology, Rutgers, The State University, New Brunswick, NJ 08903, USA
}

Received March 6, 2003

\begin{abstract}
Methamphetamine (METH)-induced neurotoxicity is characterized by a long-lasting depletion of striatal dopamine (DA) and serotonin as well as damage to striatal dopaminergic and serotonergic nerve terminals. Several hypotheses regarding the mechanism underlying METHinduced neurotoxicity have been proposed. In particular, it is thought that endogenous DA in the striatum may play an important role in mediating METH-induced neuronal damage. This hypothesis is based on the observation of free radical formation and oxidative stress produced by autooxidation of DA consequent to its displacement from synaptic vesicles to cytoplasm. In addition, METH-induced neurotoxicity may be linked to the glutamate and nitric oxide systems within the striatum. Moreover, using knockout mice lacking the DA transporter, the vesicular monoamine transporter 2, c-fos, or nitric oxide synthetase, it was determined that these factors may be connected in some way to METH-induced neurotoxicity. Finally a role for apoptosis in METHinduced neurotoxicity has also been established including evidence of protection of bcl-2, expression of p53 protein, and terminal deoxynucleotidyl transferase-mediated dUTP nick-end labeling (TUNEL), activity of caspase-3. The neuronal damage induced by METH may reflect neurological disorders such as autism and Parkinson's disease.
\end{abstract}

Keywords: methamphetamine, neurotoxicity, free-radical, dopamine, apoptosis

1. Introduction 178

2. Neuronal damage caused by methamphetamine (METH) 179

a. Neurochemical depletion

b. Nerve terminal degeneration

c. Related drugs and neuronal damage

3. Hypotheses regarding the mechanism of METHinduced neurotoxicity 186

a. Formation of reactive oxygen species and oxidative stress

b. Glutamate and nitric oxide

c. Apoptosis

4. Behavioral deficits following METH-induced neuronal damage 187

a. Self-injurious behavior

b. Hyperthermia

c. Animal model of Parkinson's disease

\section{Introduction}

Recently, several hypotheses regarding the mecha-

*Corresponding author. FAX: +81-744-25-7657

E-mail: nakashim@naramed-u.ac.jp

Invited article nism underlying methamphetamine (METH)-induced neurotoxicity have been presented $(1-3)$. An understanding of this underlying mechanism may contribute 
to medical treatment of autism and schizophrenia as well as the schizophrenic-like symptoms observed in individuals who have abused amphetamine (AMPH)like compounds. In addition, METH-induced dopaminergic toxicity has long been considered to be one of the most important animal models of Parkinson's disease (4). In this regard, a number of recent studies have employed knockout (c-fos, dopamine (DA) transporters, vesicle monoamine tranporter 2 , nitric oxide synthetase (NOS)) and transgenic mice (over-expressing superoxide dismutase (SOD)) that have advanced our understanding of the mechanisms responsible for METHinduced neurotoxicity. Moreover, METH has been shown to increase the transcription factor activator for protein- 1 and cyclic adenosine monophosphate response element binding protein and also to act directly on the nucleus of mensencephalic cells (5). However, despite the importance of this model, there have been very few reviews either summarizing the historical significance or assimilating the current molecular research. Accordingly, the objective of this review is to integrate the historical background work that established METH as a neurotoxin and to integrate this with recent genetic manipulations that shed light on the mechanism of METH-induced neurotoxicity.

\section{Neural damage caused by METH}

\section{a. Neurochemical depletion}

AMPH and METH are potent central nervous system (CNS) stimulants with additional peripheral sympathomimetic effects. They have been used clinically in the treatment of obesity, minimal brain dysfunction, narcolepsy, depression and to counter fatigue and are also subject to widespread abuse. Following the acute administration of the AMPHs there is an increase in blood pressure, heart rate, respiration, sweating and tremor. The behavioral manifestations include species specific stereotypic behavior, anorexia, sleeplessness, hyperexcitability, and hyperactivity. Performance on operant tasks is sometimes enhanced by low doses of AMPHs but, for the most part, the drug will have disruptive effects $(6,7)$. With the repeated administration of the AMPHs, supersensitivity develops to some of the effects (e.g., increased motor activity and stereotypic behavior; (8)) while tolerance is observed to others (e.g., anorexia or operant performance disruption; $(7,9))$. Humans who self-administer high doses of the AMPHs sometimes manifest a pattern of behavior that is difficult to distinguish from paranoid schizophrenia. This schizophrenic-like syndrome may last for years after withdrawal of the drug (10).

The above behavioral effects of acute or chronically administered AMPHs are thought to be mediated through actions on the central monoamine systems. AMPH and METH are indirect agonists, causing the release of newly synthesized norepinephrine (NE) and DA and blocking the reuptake of these transmitters from the synapse (11). In addition, the amphetamines are potent inhibitors of monoamine oxidase. Collectively, these effects lead to an increase in the concentration of catecholamines in the synapse as well as an overall increase in catecholaminergic activity in the brain (12). Alpha-methyl-tyrosine (AMT) attenuates the releasing action of the AMPHs while reserpine will potentiate it (13). Acute administration of AMPH causes a transitory decline in central NE and DA in various brain regions (14), an effect most likely consequent to a temporary inhibition of tyrosine hydroxylase activity. In addition to their actions on the catecholamines, the AMPHs have been shown to increase serotonin $(5-\mathrm{HT})$ release and turnover and it has been suggested that 5-HT is intimately involved in mediating many of the behavioral effects of the AMPHs $(15,16)$. Finally, the repeated administration of low doses of AMPH was shown to cause a reduction in the number of DA and NE receptors $(17,18)$. However, using behavioral measures of receptor responsiveness, others have reported a supersensitivity develops $(19,20)$. This discrepancy may be partly resolved by the observation that repeated administration of low doses of AMPH yields supersensitivity in striatal DA receptors and diminished accumbens DA receptor numbers (21). The objective of this review is to examine the long-lasting neurotoxic actions that the AMPHs exert on monoaminergic neurons.

Monoamine depletions across species: Over the past 25 years, we and others have demonstrated that the repeated administration of high doses of AMPH or METH leads to long-lasting depletions of central monoamine levels. These depletions are accompanied by additional profound changes in other neurochemical indicies suggesting permanent neuron damage induced by the AMPHs. In the initial reports $(22,23)$, rhesus monkeys received METH in low doses eight times per day. As they became tolerant to the debilitating effects of the drug the dosage was increased. This continued for a period of four to six months at which time they were receiving a total of $52 \mathrm{mg} / \mathrm{kg}$ per day. The monkeys were allowed to survive for a period of six months after which they were sacrificed and regional brain assay of transmitter levels was conducted. It was observed that the METH-treated monkeys had significantly reduced regional DA and NE levels with respect to control monkeys. In other words, it appeared that the repeated administration of METH caused permanent neuron 
changes.

This was an important observation and the first question asked in regard to further exploration concerned species differences. Rhesus monkeys, guinea pigs and humans metabolize METH through oxidative deamination while rats metabolize the compound primarily through para-hydroxylation (24). Accordingly, high doses of METH were administered to groups of rats and guinea pigs for a period of 30 days. The total daily dose of up to $50 \mathrm{mg} / \mathrm{kg}$ was divided into two subcutaneous injections spaced twelve hours apart. After a two-week waiting period following the last injection, which is adequate for the body to clear the drug, the animals were sacrificed and regional brain assays performed as above. It was observed that striatal DA levels of drug-treated subjects were depleted to about $50 \%$ of control values. Furthermore, these depletions appeared to be dosedependent. Interestingly, the NE levels of the various brain regions were not depleted in the rats or guinea pigs (25). Thus, it became apparent that, despite the fact that the AMPHs were equally efficacious in acting as DA and NE agonists, the central dopaminergic system appeared more sensitive to their toxic actions. Nonetheless, in three different species, the repeated administration of METH was shown to cause long-lasting depletions of central DA.

This depletion was reported to last six months in rhesus monkeys and for at least two weeks in rodents. In order to determine if the depletion was transitory or long-lasting in the rodent, groups of rats were treated with high doses of METH for 30 days and allowed to survive for 2,4 , or 8 weeks after the last injection before they were sacrificed for regional brain assay. It was observed that after all three waiting periods, there was a significant depletion of striatal DA levels. Furthermore, there was no tendency toward recovery from the depletion over the 8-week waiting period (26). Later, this depletion was found to be stable for at least 6 months after the last injection (27). This long-lasting nature of the DA depletion was interpreted as an indication that it was permanent and not due to any remaining METH affecting the steady state levels. That is, if there were drug remaining in the animal at the time of sacrifice, there would be a trend toward recovery of DA concentrations over the 2 -week to 6-month periods as more and more drug was cleared. This was not the case.

In a parametric study of the long-lasting striatal DA depletions, groups of rats received different daily doses of METH $(12.5,25$, or $50 \mathrm{mg} / \mathrm{kg}$ per day) for 40,20 , or 10 days, respectively, such that each rat received the same total dose of METH. Once again, a 2-week waiting period was allowed between the last injection and sacrifice. It was observed that the rats receiving the two higher doses of METH were significantly depleted of striatal DA, whereas those receiving the lowest daily dose for a longer period of time were not affected. In a counterpart to this study groups of rats received 12.5, 25,50 , or $100 \mathrm{mg} / \mathrm{kg}$ per day for four days and were allowed to survive for two weeks. Only the two larger daily doses of METH induced DA depletions (26). This was important because the clinical dose of METH is quite low even though treatment may be maintained for prolonged periods as in minimal brain dysfunction. Based on these early rat data, it appeared that the clinical use of the AMPHs might not be associated with neuronal damage in humans. Nonetheless, while the doses shown to induce the long-lasting depletion in rats are high, they are not out of the realm of human drug abuse (28), and there was some indication that primates may be more sensitive than rodents.

These issues were addressed in more recent studies $(29,30)$ wherein $2.0 \mathrm{mg} / \mathrm{kg}$ of AMPH or METH was administered to vervet monkeys in two i.m. injections spaced four-hours apart. They observed a substantial and long-lasting depletion of striatal DA one month later but by three months there was evidence of a partial but significant recovery. Of importance, these authors were able to attribute the recovery to increases in DA synthesis (30). The $2.0 \mathrm{mg} / \mathrm{kg}$ dose used in these studies was considerably lower than those used in the rodent studies, yet the magnitude of the DA depletion was quite comparable. This indicates that the primates may be more sensitive to the toxic actions of the AMPHs than the rodents. However, there was a recovery observed in these monkeys not observed in the rodents nor in the rhesus monkeys treated with the higher doses of METH. Therefore, it must be remembered that the doses administered to the vervet monkeys were comparatively low doses administered in just a few injections by a different route as compared to the rhesus monkey and rodent studies.

From the above studies, it is clear that the AMPHs do exert a toxic action in a variety of species and this raises the question about the safety of the drug in humans. One of the first reports to directly address this was by Wilson et al. (31). They examined brain tissue from humans who had abused AMPHs long before they had died. Compared to controls, it was observed on autopsy that those humans who had abused METH were shown to have deficits in striatal DA, tyrosine hydroxylase activity, and the DA transporter (32). These markers collectively indicate that the abused AMPHs had likely damaged the striatal dopaminergic system, though not to a point where behavioral symptoms were obvious. Likewise, imaging studies on humans demonstrated a long-lasting reduction in the number of DA transport 
pumps in the striatum of those who previously selfadministered either METH or methcathinone (33). Although these human studies are complicated in the sense that the subjects did use numerous other substances, it may be concluded that AMPHs are exerting neurotoxic actions in virtually all mammalian species. It remains to be determined if the comparatively low doses prescribed for minimal brain dysfunction or reduction in food intake also exert any deleterious effects on the dopaminergic system.

As was mentioned earlier, METH acts as an indirect agonist, causing the release of stored transmitters. It was initially postulated that the release of large amounts of the transmitter by the high concentrations of the drug reaching the CNS may exert an inhibitory feedback effect, thereby resulting in transmitter depletion (34). That is, the drugs were not causing neuronal damage but rather causing a compensatory inhibition of transmitter synthesis. This interpretation now seems unlikely in view of the long-lasting nature of the depletion and, in addition, a similar psychomotor stimulant, methylphenidate, was found to not cause any long-lasting changes. Methylphenidate is an indirect agonist which would be expected to cause a similar feedback inhibition, yet no such alteration was observed following the administration of comparable doses of the methylphenidate to rats or rhesus monkeys (ref. 35, see below). This observation led to the tentative conclusion that some characteristic of the parent AMPH molecule (or of its metabolites) was directly toxic to the neuron.

In the studies with the rhesus monkeys, the METH was administered eight times per day via automaticallycontrolled peristaltic pumps. These regular infusions assured a fairly constant plasma METH concentration throughout the day. In the early studies with rodents, the drug was injected subcutaneously twice per day at 12-h intervals. Later, this treatment regimen was shortened to four injections spaced at 2-h intervals. In any case, the subcutaneous route allows for a slower absorption and blunted swings in the peak and nadir plasma concentrations with respect to intraperitoneal or intravenous injections. On the basis of these data, it was concluded that the increased duration of some critical plasma AMPH level heightens the likelihood of neuronal damage. Several studies address this question directly.

Steranka and Sanders-Bush (36) used Alzet minipumps to infuse about $50 \mathrm{mg} / \mathrm{kg}$ per day of AMPH subcutaneously to mice for 1 week. These pumps have a continuous uniform infusion rate assuring a constant drug concentration. When the mice were assayed 2 weeks after removal of the pump, they too were depleted of striatal DA to about $50 \%$ of the control with no change in NE or 5-HT in any region assayed. Fuller and Hermrick-Luecke (37) used iprindole to inhibit para-hydroxylation of AMPH, thereby extending the drug half-life. They observed caudate DA depletions in rats one week after a single AMPH injection. These latter studies confirm the notion that maintenance of some critical plasma level of AMPH is critical. If the drug is infused continuously, substantially lower doses are required to cause significant catecholamine depletions. When there is a long inter-injection interval, larger doses and a route of administration slowing the absorption are required to bridge that interval by maintaining high plasma levels of the drug.

Up until this point, the effects of METH on the catecholaminergic system have been discussed. It should be pointed out that AMPH and METH have been shown to cause long-lasting effects on the serotonergic system as well. This should not be surprising since the halogenated derivatives of AMPH, parachloroamphetamine (PCA), has been used as a specific serotonergic toxin for some time. Both METH and PCA cause a longlasting 5-HT depletion, alter tryptophan hydroxylase activity, and decrease the number of 5-HT transport pumps (37). In addition, 5-HT levels of various brain regions were reported to be depleted following the repeated administration of AMPH to cats $(38,39)$. These depletions were accompanied by reductions of both DA and NE. However, in the cats, only the DA and NE levels were still reduced fourteen days after treatment. When relatively higher doses of METH were administered to rats, the depletion of 5-HT was found to be long-lasting and of greater magnitude than the accompanying DA depletions (40). In addition, the depletion of DA and 5-HT was greatest in the striatum and the most notable area of resistance was the hypothalamus. Friedman et al. (41) administered $12.5 \mathrm{mg} / \mathrm{kg}$ of METH to rats in four subcutaneous injections and observed long-lasting depletions of striatal DA as well as hippocampal and frontal cortex 5-HT. As above, a partial recovery was noted over a seven-month period but hippocampal 5-HT remained low throughout.

Thus, the repeated administration of the AMPHs results in long-lasting depletions of brain monoamines. These depletions are observed in a wide-range of species and across most brain regions. Differences in dose and route of administration make direct comparisons somewhat difficult, but it does appear that primates are more sensitive than rodents and that, with lower doses, there will be a partial recovery (Table 1).

Age-dependent effects: The AMPHs and methylphenidate have been used in the treatment of minimal brain dysfunction and have been administered by 
Table 1. METH-induced monoamine depletion and recovery following METH-induced neurotoxicity

\begin{tabular}{|c|c|c|c|c|c|c|c|c|}
\hline \multirow{2}{*}{$\begin{array}{c}\text { Dose } \\
(\mathrm{mg} / \mathrm{kg})\end{array}$} & \multirow{2}{*}{$\begin{array}{l}\text { Interval } \\
\times \text { Times }\end{array}$} & \multirow{2}{*}{ Route } & \multirow{2}{*}{ Species/Strain/Sex } & \multirow{2}{*}{ Region } & \multirow{2}{*}{$\begin{array}{c}\text { Period } \\
\text { after treatment }\end{array}$} & \multicolumn{2}{|c|}{ Recovery of control (\%) } & \multirow{2}{*}{$\begin{array}{l}\text { Author } \\
\text { Reference No. }\end{array}$} \\
\hline & & & & & & DA & 5-HT & \\
\hline \multirow[t]{3}{*}{50} & $24 \mathrm{~h} \times 30$ & s.c. & rats/Sprague-Dawley/male & caudate nucleus & 2 weeks & 43 & - & Wagner et al. (1980) \\
\hline & & & & & 4 weeks & 64 & - & 26,35 \\
\hline & & & & & 8 weeks & 57 & - & \\
\hline \multirow[t]{3}{*}{10} & $2 \mathrm{~h} \times 4$ & i.p. & mice $/ \mathrm{CD} /$ male & striatum & 1 day & 31 & 66 & Ali et al. (1994) \\
\hline & & & & & 1 week & 34 & 74 & \\
\hline & & & & & 2 weeks & 54 & 77 & \\
\hline \multirow[t]{3}{*}{12.5} & $2 \mathrm{~h} \times 4$ & s.c. & rats/Long-Evans/male & caudate nucleus & 48 days & 41 & 28 & Friedman et al. (1998) \\
\hline & & & & & 139 days & 81 & 51 & 41 \\
\hline & & & & & 237 days & 81 & 67 & \\
\hline \multirow[t]{3}{*}{5} & $2 \mathrm{~h} \times 4$ & s.c. & rats/Ficher-344/male & striatum & 1 week & 47 & - & Cass and Manning (1999) \\
\hline & & & & & 6 months & 80 & - & \\
\hline & & & & & 12 months & 92 & - & \\
\hline 40 & $2 \mathrm{~h} \times 4$ & i.p. & rats/Sprague-Dawley/male & striatum & 6 weeks & 46 & 33 & $\begin{array}{l}\text { Sabol et al. (2001) } \\
155\end{array}$ \\
\hline
\end{tabular}

i.p.: intraperitoneal injection, s.c.: subcutaneous injection, DA: dopamine, 5-HT: serotonin. (Modified from Ref. 3 with permission)

women during pregnancy $(42,43)$. The administration of METH or AMPH to pregnant rats or mice was shown to result in behavioral alterations in the offspring including increases (44) or decreases in activity (45), but little change in associative task performance (46). Catecholamine levels of these offspring have been reported to be increased $(47,48)$, decreased $(49)$, or unaltered (44). In addition, the metabolism of catecholamines is reportedly increased in the offspring (44).

Interpretation of these results must be guarded, however, since the AMPHs have a multitude of effects on the pregnant rat which may, in turn, affect the fetus' oxygen supply, nutrients, or even the amount of plasma amines exchanged between the fetus and the mother. These could all result in long-lasting transmitter depletions in the viable offspring. Indeed, there is often diminished litter size of METH-treated mothers (49). A suitable control for these experiments might be the concomitant administration of methylphenidate to other pregnant rats and subsequent observation of the offspring. No long-lasting depletion would be expected but if one were to occur, some of the previously mentioned nonspecific effects would have to be considered as the cause of the depletion.

When AMPHs are administered directly to neonatal rats, similar long-lasting depletions of striatal DA are observed as has been reported in adults. This direct administration to the neonate circumvents the problems cited above with respect to drug administration to pregnant rats. Litters of rats received one of three doses of either METH or AMPH from days 10 to 40 of life and were killed two weeks later. METH-treated rat pups had dose-dependent depletions that were somewhat reduced when compared with comparable treated adults (50). This is not surprising since AMPH's effects are attenuated in the neonate on a number of other measures as well, including stereotypic behavior (51), anorexia (52), and lethality (53). However, sensitivity to AMPHs is not always low in neonates. Levine et al. (54) administered low doses of AMPH ( 1 to $4 \mathrm{mg} / \mathrm{kg}$ ) to kittens; they gave three injections with at least 10 days between each injection. One month to one year after these injections, the cats exhibited substantial depletions of caudate DA along with reductions in tyrosine hydroxylase activity and spontaneous neuronal activity. The complication in interpreting this latter study is that cats, as a species, are extremely sensitive to the neurotoxic effects of the AMPHs. Thus, while these kittens did show a neurotoxic response to AMPH at doses lower than those required for rodents, the kittens still appeared to be more resistant as compared to adult cats.

In a comprehensive study of the ontogeny of METHinduced neurotoxicity, Vorhees and $\mathrm{Pu}$ (55) showed that younger rat pups (before about 40 days of age) were quite resistant to the neurotoxic effects of METH as evidenced by tyrosine hydroxylase and glial fibrillary acidic protein (GFAP) analysis. Yet, surprisingly, the 
METH did produce persistent deficits in unconditioned behaviors that lasted into adulthood. Somewhere between days 40 and 60 of life, the rats began to show the sensitivity to the neurotoxic effects of METH (again in the tyrosine hydroxylase and GFAP measures), but as adults, they were less sensitive to the behavioral deficits. These authors were partly able to resolve this issue by showing that, in adults, the neurotoxic regimen actually causes a sensitization to stimulants, and they were able to attribute this sensitization to alterations in DA receptor number (56).

Finally, the age-dependent effects of the amphetamines extend to older animals with aged mice being more sensitive to the DA-depleting effect (57). In this study, young adult mice or aged mice were treated with $\mathrm{METH}$ at $12.5 \mathrm{mg} / \mathrm{kg}$ per injection for four injections and sacrificed 2 weeks later. This age-dependent increase in sensitivity to METH correlated with an agedependent increase in monoamine oxidase B and appears to reflect an age-dependent increase in sensitivity to the DA release caused by these agents $(57,58)$. Thus, with respect to the age-dependent effects, it appears that younger animals are partially protected from the neurotoxic effects of the AMPHs because they have less DA release together with lower levels of monoamine oxidase $\mathrm{B}$.

Sex-dependent effects: Most of the work described thus far has been conducted on male subjects. It was reported, however, that male mice are more sensitive to the neurotoxic effects of the AMPHs than are females $(59-61)$. Although the difference was slight, this effect has been replicated in rats where the significant effect was shown to be more dependent on hyperthermic effects rather than sex (62). Furthermore, Yu and Liao (60) observed that the 5-HT depletion following METH was four-fold greater in males as compared to females.

The reason for this differential sensitivity to METH in males versus females remains elusive. However, Yu and Liao (60) were able to attribute a portion of the sexrelated differences in sensitivity to the neurotoxic effects of METH to protective effects of estrogen. Specifically, they observed that the most severe depletions followed METH treatment administered during diestrus, whereas in contrast, the least severe depletions followed METH treatment during proestrus. These sex-related differences in sensitivity to METH-induced neurotoxicity have important ramifications for Parkinson's disease (see below).

Other neurochemical markers of toxicity: A number of studies have reported long-lasting decreases in tyrosine hydroxylase activity in rats exposed to high doses of
METH $(34,63,64)$. The initial interpretation was that excessive release of DA caused by the METH initiated a feedback loop shutdown of DA synthesis (e.g., ref. 34). As noted, this notion is not likely in view of the longlasting nature of the phenomenon and also because electrolytic lesions disrupting the presumed feedback loop failed to alter the decrease in tyrosine hydroxylase activity (65). The decrease in tyrosine hydroxylase activity has been reported after very low doses of continuously infused AMPH and has been reported to last 110 days after drug is removed $(54,64)$. In addition, these studies on alterations of tyrosine hydroxylase activity induced by the AMPHs have reported concomitant depletions of DA (63). The decrease in tyrosine hydroxylase activity was prevented by pretreatment with AMT or simultaneous injection of chlorpromazine (34, 63). Interestingly, massive doses of L-dopa plus R044602 plus AMT plus METH resulted in decreased enzyme activity (34). This is suggestive that the synthesis of DA is required for METH to decrease tyrosine hydroxylase activity. Unfortunately, interpretation of these results is difficult since only a 6-h waiting period between the injection and the sacrifice was used and because there was undoubtedly a great deal of drug by drug interactions that were not necessarily planned or interpretable. Finally, the decrease in tyrosine hydroxylase activity is accompanied by a reduced expression of the tyrosine hydroxylase mRNA as well as the protein itself (66).

As might be expected, tryptophan hydroxylase activity was also found to be reduced following the repeated administration of the AMPHs $(38,39,65,67)$. This decrease in 5-HT synthesis was reported following the repeated administration of AMPHs to rats or cats, respectively. These decreases in enzyme activity were accompanied by reduced 5-HT levels and reduced 5-HT metabolite levels as well. Both labs agreed that the 5-HT system appears to be more sensitive to the neuronal alterations induced by the AMPHs than the catecholamine systems.

These studies on tyrosine and tryptophan hydroxylase activity provide evidence that a second neuronal process in addition to transmitter storage is affected by the AMPHs. However, with this information alone, it is still not possible to discern whether the depletions are due to a decrease in synthesis or if this decrease in synthesis is actually a reflection of a decrease in the number of neurons. Fukumura et al. (68) did show that the extent of the reduction in tyrosine hydroxylase activity tended to correlate with the extent of the acute rise in body temperature and later DA depletion, but again the waiting period was rather too short to be convincing that there was long-lasting damage. 
A third process of the neuron classically studied is that of the transmitter transport pump. Wagner et al. (26) reported a significant decrease in the number of DA transport pumps with no change in the affinity of the remaining sites following the repeated administration of METH to rats. This result was also reported by Steranka and Sanders-Bush (36) in mice treated with high doses of AMPH. As a control procedure, rats were treated with high doses of either AMPH or methylphenidate and allowed to recover for 2 weeks. As expected, the AMPH caused a reduction in the number of uptake sites, while the methylphenidate had no effect (35). Thus, a third neuronal process is also affected, and a picture begins to emerge that the AMPHs are quite toxic to certain neurons.

In addition, there is now evidence that the remaining neurons have an increase in catecholamine turnover as measured by the DOPA accumulation and DOPAC/DA ratio techniques (69). Likewise, following treatment with $5 \mathrm{mg} / \mathrm{kg}$ of METH (administered in four injections spaced 2-h apart), Cass and Manning (70) found a reduction in potassium-induced DA release. They reported that there was a recovery from this effect over a 1-year period. However, collectively, it appears that the damage caused by the AMPHs results in a compensatory increase in DA turnover, a classic compensatory strategy following neural injury.

Finally, one last biochemical marker is the effect of the AMPHs on the post-synaptic receptor. McCabe et al. (71) showed that there was a reduction in DA receptor number shortly after the high-dose administration of METH to rats. This observation is consistent with the notion that the high-doses of METH would release DA in sufficient amounts to cause receptor down-regulation. Of interest, the effect only lasted about one week with the animals showing recovery after that time. Since the AMPHs are causing long-lasting depletions of DA, one would predict a compensatory up-regulation of the post-synaptic receptors. This effect was observed by Fields et al. (72); again, the receptor sensitivity following the DA lesion is considered to be one of the classic compensatory strategies following neuronal injury.

Regional changes: Thus far, the damage resulting from AMPH or METH administration has been discussed primarily in the context of the striatum. This large telencephalic region is richly innervated by dopaminergic and serotonergic neurons and damage to its terminals has been linked to Parkinson's disease (see below). However, the AMPHs do cause permanent damage to other brain regions as well. Morgan and Gibb (73) administered $75 \mathrm{mg} / \mathrm{kg}$ of METH to rats in five doses spaced 2-h apart. They observed long-lasting
(30 days) decreases in tyrosine and tryptophan hydroxylase activity in the striatum and these decreases in enzyme activity were accompanied by depletions of DA and 5-HT. Of interest, the magnitude of the enzyme activity reduction and depletion of the transmitter levels were not uniform throughout the brain. Rather, they observed the greatest effect in the striatum, but virtually no change in the nearby accumbens or in the median eminence. Furthermore, they observed that when there was a differential sensitivity across brain regions, the effect invariably was larger in the serotonergic system as compared to the dopaminergic system. Thus, the AMPHs cause a selective toxicity, varying across brain region and cell type.

The striatum itself does not receive a homogenous projection of nigral dopaminergic fibers but rather is topographically dissimilar, with clusters of DA-rich striasomes. The damage caused by METH administration to mice parallels these DA rich regions with local DA concentration being the best predictor of METHinduced DA depletion (74). Of interest, these authors also demonstrated that the METH-induced depletion of DA did not correlate with the local concentration of DA transport pumps. Somewhat related to this, Eisch et al. (75) showed that a METH regimen caused a greater reduction of mazindol binding (a measure of the number of DA transport pumps) in the ventral striatum as compared to the accumbens or dorsal striatum.

\section{b. Nerve terminal degeneration}

The collective action of the AMPHs on neuronal function thus far has been discussed in the context of longlasting decreases in the steady state levels of the transmitters, the decrease in the activity of the rate-limiting enzymes for production of these transmitters, a decrease in the activity of the transport pumps that remove the transmitter from the synapse, and an overall increase in the turnover of the transmitter release in the remaining neurons. The effects clearly point to nerve terminal damage which should be manifest in morphological analysis.

In the earliest morphological study, Miyakawa et al. (76) administered METH to guinea pigs at $1 \mathrm{mg} / \mathrm{kg}$ per day for up to 1 year. They observed a coalescence of axonal membranes with those of the terminals and dendrites as well as an increase in the number of coated vesicles. These effects were observed throughout the telencephalon and diencephalon. They interpreted these observations in terms of altered neural conduction, perhaps associated with the neurological and psychiatric symptoms observed by humans who chronically abuse METH. In a subsequent study, Ellison et al. (64) who administered AMPH continuously to rats, observed 
swollen nerve fibers in the striatum and associated this with the long-lasting depletion of DA. Likewise, Lorez (77) administered METH in six doses of $15 \mathrm{mg} / \mathrm{kg}$ to rats and sacrificed them 6 to 11 days later. It was observed that the striatal region showed swelling of the nerve terminals suggestive of neuronal damage, an effect not apparent in the accumbens or olfactory tubercle. Finally, when AMPH was continuously infused for 7 days in mice, it was again observed that there was swelling of the nerve terminals (78). These authors further demonstrated that the AMPH damaged the dopaminergic fibers but spared the noradrenergic and serotonergic fibers.

The above studies clearly demonstrate that morphological changes follow the repeated administration of METH, but these morphological changes do not necessarily indicate nerve damage. Actual neuronal degeneration has been observed using the Fink-Heimer stain providing convincing evidence that the neurons are actually damaged by the AMPHs. These degenerating terminals would be difficult to interpret if it were not for the above mentioned alterations in catecholaminergic and serotonergic processes plus the additional observation that the GABA and cholinergic neurons appear unaffected by the drug regimen (79). In a similar study, Hess et al. (80) administered four doses of $10 \mathrm{mg} / \mathrm{kg}$ METH to mice and found loss of tyrosine hydroxylase stained neurons together with a marked gliosis and increased GFAP.

Other brain regions show morphological damage following METH. Eisch et al. (81) used the fluoro-jade technique to label damaged neurons and observed damage in layers III and IV of the parietal cortex. Likewise, neuronal degeneration also appears in the hippocampus, and this is likely linked to the 5-HT depletion in this region (30).

Although there is clear evidence of nerve terminal damage and degeneration, it should be pointed out that there has been some controversery with respect to the substantia nigra cell bodies. Some have reported that these cell bodies are not affected by treatment with the AMPHs (82). In part, this may explain the ability of these animals to recover over time. However, as above, differences in dose and treatment regimen may underlie the apparent discrepancies. This controversy was decidedly resolved by Sonsalla et al. (83) who treated mice with high doses of METH sufficient to cause a $90 \%$ depletion of striatal DA. On histological examination of the substantia nigra, they observed significant (approaching 50\%) loss of cell bodies as evidenced by tyrosine hydroxylase staining as well as cresyl violet staining. With this critical observation, it becomes clear that the AMPHs are capable of causing extensive neuronal damage as reflected in a variety of neurochemical markers, nerve terminal degeneration, and loss of cell bodies.

\section{c. Related drugs and neuronal damage}

As noted above, AMPH and METH are potent releasers of the monoamines and cause extensive damage to these cells. Furthermore, it was noted that an otherwise comparable stimulant, methylphenidate, did not cause damage to these same neurons. A critical difference between these drugs is that methylphenidate does not cause the release of the monoamines, but rather blocks their reuptake. In fact, when co-administered, the DA transport blockers actually prevent the damage caused by METH (84). This action is linked to the ability of the transport pump blockers to prevent accumulation of the METH into the neuron and/or their ability to block the accumulation of toxic products formed in the synapse following the drug-induced transmitter release.

A number of other agents have been tested for their potential to induce depletions similar to the AMPHs. Cathinone is structurally related to the AMPHs and acts through release of the catecholamines. It was found to cause long-lasting depletions of striatal DA at doses quite comparable to AMPH (85). This toxic effect was recently observed in humans as well (32). Cocaine is structurally dissimilar to the AMPHs and acts primarily through blockade of reuptake of the catecholamines and has not been found to cause these effects despite administration of rather massive doses (86). Likewise, neither phencyclidine nor phenylpropanolamine have been found to cause these types of depletions despite administration of heroic doses $(87,88)$. Both of these compounds act primarily as DA uptake inhibitors. Thus, it appears that DA releasers do cause the neuronal damage while the DA transport blockers not only do not cause the neuronal damage but actually protect subjects against the toxic action of the releasers.

This analogy may be extended to the serotonergic system as well. Specifically, fenfluramine (a releaser of 5-HT) administered to rats in high doses caused neuronal damage to raphe serotonergic neurons as evidenced by Nissl and silver staining (89) while high doses of fluoxetine (an uptake blocker) did not. Finally, one agent which has received much attention is 3,4methylenedioxyamphetamine (MDMA or ecstasy). The AMPH analogue is a potent releaser of 5-HT and is subject to abuse. It has been shown to be toxic to serotonergic nerve terminals in rats (90) and is likely toxic to humans who have self-administered high doses of the drug. 


\section{Hypotheses regarding the mechanism of METH- induced neurotoxicity}

\section{a. Formation of reactive oxygen species (ROS) and oxidative stress}

It appears that METH-induced neurotoxicity may be related to its ability to release monoamine transmitters. AMT, a catecholamine synthesis inhibitor, prevents the toxic effects of METH $(91,92)$, whereas L-dopa administration enhances the toxic effect of METH on catecholaminergic neurons as well as the accompanying decreases in 5-HT and 5-HIAA (93). Therefore, the mechanism of METH-induced neurotoxicity for all monoaminergic cell types may lie primarily with the dopaminergic system in the striatum and the interaction between METH-induced release of DA and its ability to inhibit monoamine oxidase.

The mechanism through which METH causes striatal dopaminergic neurotoxicity is still unclear, although two major hypotheses have been proposed. First, it has been suggested that METH-induced DA release is responsible for the METH-induced neurotoxicity; the excess DA caused by the DA transporter-mediated outward transport of DA is thought to encourage formation of 6-hydroxy $(\mathrm{OH}) \mathrm{DA}$ by auto-oxidation of DA in the elevated extracellular DA concentrations (91, 94, 95). However, 6-OHDA is extremely labile and hydrogen peroxide is generated during autooxidation of DA $(96,97)$. The formation of DA-related ROS such as superoxide and hydroxyradicals appears to play an important role in METH-induced neurotoxicity. Moreover, administration of antioxidants, such as ascorbic acid or vitamin E, caused attenuation of METH-induced neurotoxicity $(98,99)$, whereas, inhibition of SOD by diethyldithiocarbamate increased its neurotoxicity (99). In addition, studies using mice over-expressing SOD have reported protection against the toxic effect of METH $(100,101)$. These reports have hinted at a role for oxygen-based free radicals in the actions of this drug (1).

Regarding formation of hydroxyl radicals, an increase in 2,3- and 2,5-dehydroxybenzoic acid (DHBA), the stable product of the reaction of salicylate with hydroxyl radicals, has been observed in striatal dialysate and tissue after treatment with a neurotoxic dose of METH (102, 103). These observations clear indicate that monoaminergic neurons are experiencing an oxidative stress following administration of the AMPHs.

An alternative hypothesis is that redistribution of DA from synaptic vesicles to cytoplasmic compartments and consequent elevation of oxidizable DA concentrations may be primarily responsible for DA terminal injury by AMPHs (104). Fumagalli et al. (105), using vesicular monoamine transport (VMAT) 2 knockout mice, indicated that disruption of VMAT potentiates METH-induced neurotoxicity in vivo and point, albeit indirectly, to a greater contribution of an intraneuronal DA redistribution rather than extraneural overflow in mediating this effect.

However, both hypotheses suggest that disruption of the delicate balance that exists among vesicular, cytoplasmatic, and extracellular DA pools may cause the neurotoxic effect of METH. Thus, although DA clearly plays an important role in METH neurotoxicity, the exact DA pool responsible for this toxicity requires further investigation (Fig. 1).

\section{b. Glutamate and NO}

It has been reported that an increase in DA release may cause a secondary release of glutamate in the striatum via a cortico-striatothalamo-cortical negative feedback loop (106). A role of this excitatory amino acid transmission in mediating METH-induced neurotoxicity has been suggested. For example, pretreatment with MK-801, an $N$-methyl-D-aspartate (NMDA) type of receptor antagonist, attenuates $\mathrm{METH}$-induced neurotoxicity (107) and METH enhances glutamate release $(108-110)$. In addtion, neural nitric oxide synthase (nNOS) knock-out mice are protected against METHinduced neurotoxicity and locomotor sensitization (111).

NMDA-receptor activation is related to stimulation of the nNOS isoform. The NMDA receptor complex opens channels that admit calcium into the cell; the binding of calcium to calmodulin activates nNOS, which produces $\mathrm{NO}$, and subsequently elicits the accumulation of cGMP $(112,113)$. NO-mediated neurotoxicity may arise from the formation of free radicals (peroxynitrite and breakdown products) (114). In addition, activation of metabotropic glutamate type 5 (mGlu5) receptors are functionally coupled to NMDA receptors. Activation of mGlu5 receptors enhances NMDA receptors in neurons (115, 116) and contributes to the development of excitotoxic neuronal death (117).

Battaglia et al. (118) reported that METH-induced neurotoxicity was primarily attenuated by the co-injection of the noncompetitive mGlu5 receptor antagonists, and these antagonists reduced the production of reactive oxygen species but did not reduce the acute stimulation of DA release induced by METH both in striatal synaptosomes and in the striatum of freely moving mice.

They conclude that endogenous activation of mGlu5 receptors enables the development of METH neurotoxicity and that mGlu5 receptor antagonists are neuroprotective without interfering with the primary mechanism of action of METH. However, both mGlu1 and 2 receptors mediate augmentation of DA release from the 


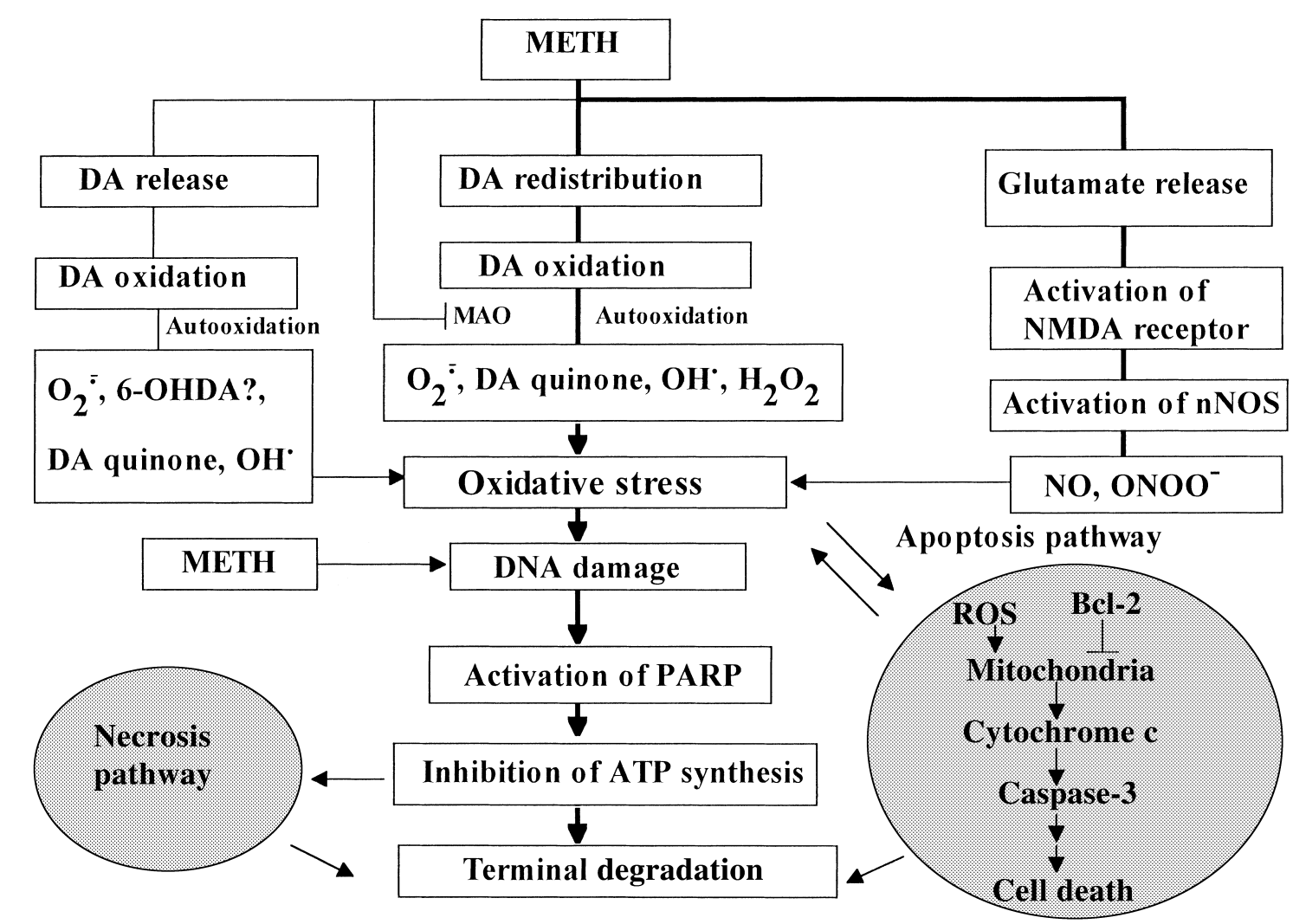

Fig. 1. Proposed mechanism for METH-induced neurotoxic pathway in striatum. MAO: monoamine oxidase. PARP: poly(ADP-ribose)-polymerase. (Modified from Ref. 3 with permission)

striatum in METH-sensitized rats (119).

Taken together, we speculate that the interaction between mGlu5 and NMDA receptors may play an important role in mediating METH-induced neurotoxicity, and the mechanism requires further investigation (Fig. 1).

\section{c. Apoptosis}

A relationship between apoptosis and METH-induced neurotoxicity in thymus and spleen has been reported (120). Moreover, there is some evidence for activation of apoptotic pathways during the toxic response to METH. For example, Cadet and coworkers have studied the degenerative processes in the central nervous system via apoptosis caused by neurotoxic doses of METH. They reported that $\mathrm{bcl} 2$, a proto-oncogene, METH caused dose-dependent apoptosis and loss of cellular viability in immortalized neural cells, whereas bcl2-over expressing neural cells were protected against these deleterious effects (121). Moreover, using primary cortical cultures from rats, AMPH analogs also caused apoptosis and activation of cell death-related genes (122). Likewise, in p53 gene (tumor suppressor)-knockout mice, METH-induced neurotoxicity in striatal dopaminergic terminals was found to be reduced compared to wild-type mice (123). These authors indicate that p53 activation might be part of the mechanism that causes the long-term deleterious effects of the neurotoxic AMPHs on the cerebral monoaminenergic system.

Recently, Deng et al. (124) reported that METHinduced cytochrome c leakage from mitochondria and the reduction of oxygen consumption occurred as early as $2 \mathrm{~h}$ after METH application to the cell culture. Subsequent to cytochrome c release, a substantial activation of the caspase cascade becomes evident starting with the early activation of caspase 9 and a more delayed cleavage of caspase 3 . These results suggest that cell death-genes in the apoptic process may play an important role for terminal degeneration caused by METHtreatment (Table 2, Fig. 1).

\section{Behavioral deficits following METH-induced neuronal damage}

\section{a. Self-injurious behavior (SIB)}

As noted above, administration of the AMPHs is followed by repetitive and stereotypic behavior which, 
Table 2. Incidence of apoptosis produced by neurotoxic dose of METH in rats and mice

\begin{tabular}{|c|c|c|c|c|c|c|}
\hline $\begin{array}{l}\text { Author } \\
\text { Reference No. }\end{array}$ & Species & Dose & $\begin{array}{l}\text { Rout } \\
\text { Times }\end{array}$ & $\begin{array}{l}\text { Marker of } \\
\text { apoptosis }\end{array}$ & $\begin{array}{l}\text { Changes in apoptosis } \\
\text { marker }\end{array}$ & Regions \\
\hline $\begin{array}{l}\text { Deng et al. (2001) } \\
156\end{array}$ & CD-1 mouse & $40 \mathrm{mg} / \mathrm{kg}$ & $\begin{array}{l}\text { single i.p. injection } \\
3 \text { days }\end{array}$ & TUNEL & positive cells $\uparrow$ & $\begin{array}{l}\text { striatum, } \\
\text { cortex }\end{array}$ \\
\hline $\begin{array}{l}\text { Jayanthi et al. (2001) } \\
157\end{array}$ & CD-1 mouse & $40 \mathrm{mg} / \mathrm{kg}$ & $\begin{array}{l}\text { single i.p. injection } \\
8,16,24 \mathrm{~h}, 7 \text { days }\end{array}$ & $\begin{array}{l}\text { TUNEL, BAX, } \\
\text { BAD, BID, Bcl-2 }\end{array}$ & $\begin{array}{l}\text { positive cells } \uparrow \\
\text { expression } \uparrow \\
\text { expression } \downarrow\end{array}$ & neocortex \\
\hline $\begin{array}{l}\text { Iman et al. (2001) } \\
158\end{array}$ & $\begin{array}{l}\text { C57BL/J6, } \\
\text { nNOS-/-, } \\
\text { SOD-Tg mouse }\end{array}$ & $10 \mathrm{mg} / \mathrm{kg}$ & $\begin{array}{l}\text { four i.p. injections } \\
\text { (2-h interval) } \\
3 \text { days }\end{array}$ & p53 protein, $\mathrm{Bcl}-2$ & $\begin{array}{l}\text { expression } \uparrow \text { (wild type) } \\
\text { expression } \downarrow \\
\text { no significant (knock-out) }\end{array}$ & striatum \\
\hline $\begin{array}{l}\text { Thiriet et al. (2001) } \\
159\end{array}$ & CD-1 mouse & $40 \mathrm{mg} / \mathrm{kg}$ & single injection & c-myc, L-myc & mRNA and protein levels $\uparrow$ & $\begin{array}{l}\text { sriatum, } \\
\text { cortex }\end{array}$ \\
\hline $\begin{array}{l}\text { Deng and Cadet (2000) } \\
160\end{array}$ & $\begin{array}{l}\text { SOD-Tg mouse, } \\
\text { C57BL mouse }\end{array}$ & $10 \mathrm{mg} / \mathrm{kg}$ & $\begin{array}{l}\text { four i.p. injections } \\
\text { (2-h interval) } \\
3 \text { days }\end{array}$ & $\begin{array}{l}\text { TUNEL } \\
\text { PARP cleavage } \\
\text { caspase } 3 \text { activity }\end{array}$ & $\begin{array}{l}\text { positive cells } \uparrow \\
\text { increase } \uparrow \\
\text { activity } \uparrow\end{array}$ & striatum \\
\hline $\begin{array}{l}\text { Deng et al. (1999) } \\
161\end{array}$ & $\begin{array}{l}\text { c-fos knock-out } \\
\text { mouse }\end{array}$ & $10 \mathrm{mg} / \mathrm{kg}$ & $\begin{array}{l}\text { four i.p. injections } \\
\text { (2-h interval) } \\
72 \mathrm{~h}, 7 \text { days }\end{array}$ & TUNEL & $\begin{array}{l}\text { positive cells } \uparrow \text { (wild type) } \\
\text { positive cells } \uparrow \uparrow \text { (knock-out) }\end{array}$ & $\begin{array}{l}\text { striatum, } \\
\text { cortex }\end{array}$ \\
\hline $\begin{array}{l}\text { Stumm et al. (1999) } \\
122\end{array}$ & Wistar rats & $\begin{array}{l}125- \\
1000 \mu \mathrm{M}\end{array}$ & $1,24,90 \mathrm{~h}$ & $\begin{array}{l}\text { DNA cleavage } \\
\text { pro-apoptotic Bcl- } \mathrm{X}_{\mathrm{S}} \\
\text { anti-apoptotic } \mathrm{BclX}_{\mathrm{L}}\end{array}$ & $\begin{array}{l}\text { increase } \uparrow \\
\text { expression } \uparrow \\
\text { expression } \downarrow\end{array}$ & $\begin{array}{l}\text { neocortical } \\
\text { neurons }\end{array}$ \\
\hline $\begin{array}{l}\text { Cadet et al. (1997) } \\
121\end{array}$ & $\begin{array}{l}\text { CSM14.1 neurons } \\
\text { (bcl-2 expressing } \\
\text { cells) }\end{array}$ & $1-3 \mathrm{mM}$ & $24 \mathrm{~h}$ & $\begin{array}{l}\text { DNAstrand breaks, } \\
\text { chromatin condensation, } \\
\text { nuclear fragmentation, } \\
\text { DNA laddering }\end{array}$ & protection $\uparrow$ & $\begin{array}{l}\text { neural cell } \\
\text { obtained from rat } \\
\text { mesencephalon }\end{array}$ \\
\hline $\begin{array}{l}\text { Iwasa et al. (1996) } \\
120\end{array}$ & Wistar rats & $25 \mathrm{mg} / \mathrm{kg}$ & $\begin{array}{l}\text { i.p. single injection } \\
4,8,24 \mathrm{~h}\end{array}$ & TUNEL & positive cells $\uparrow$ & $\begin{array}{l}\text { thymus, } \\
\text { spleen }\end{array}$ \\
\hline
\end{tabular}

Bcl-2: anti-death proto-oncogene, c-myc and L-myc: proto-oncogenes, PARP: poly-ADPribose-polymerase, TUNEL: terminal deoxynucleotidyl transferase-mediated dUTP nick-end labeling, expression $\uparrow$ : up-regulated expression, expression $\downarrow$ : down-regulated expression. (Modified from Ref. 3 with permission)

if the doses are high enough or if the injections are repeated often enough, can advance to SIB. In humans, these behaviors are manifest as self-biting, head-banging, scratching, cutting, hair-pulling, as well as other behaviors leading to tissue damage. SIB are among the most difficult to manage, usually requiring protective devices and institutionalization. As a symptom pattern, SIB occurs at high rates in autism (125), Lesch-Nyhan syndrome $(126,127)$, mental retardation (128), Tourette's syndrome (129), and borderline personality disorder (130). It appears that the acute appearance of SIB associated with administration of the AMPHs to rodents may accurately predict the later neurotoxicity and at the same time serve as a model for the study of this disabling symptom in humans.

The neurochemical basis of SIB remains unknown, although considerable evidence points to involvement of central DA neurons. This evidence includes the following: a) the primary treatment for SIB is administration of dopaminergic antagonists $(125)$; b) the primary animal model of SIB involves the neonatal administration of 6-OHDA with subsequent agonist administration $(131,132)$; and c) Lesch-Nyhan patients, who engage in severe SIB, exhibit dramatic depletions of central DA from birth together with intense DA receptor supersensitivity $(133,134)$.

We have previously demonstrated that in intact mice, high doses of the AMPHs do induce SIB (135, 136) and that these behaviors are associated with DA release, dopaminergic toxicity, and hyperthermia (136). Furthermore, we have demonstrated that there are considerable differences in sensitivity to stimulantinduced SIB across various strains of mice (135). For example, BALB/c mice are derived from a highly inbred strain and have been widely used in various animal models. Recently, we found that BALB/c mice exhibit an increased sensitivity to METH-induced striatal dopaminergic neurotoxicity as compared to C57Bl/6 mice (135). In addition, we reported that repeated administration of METH caused an intense 
$\mathrm{SIB}$ in $\mathrm{BALB} / \mathrm{c}$ but not $\mathrm{C} 57 \mathrm{Bl} / 6$ mice and this acute behavioral response predicted later $\mathrm{METH}$-induced striatal DA neurotoxicity $(136,137)$.

We further demonstrated that the appearance of SIB was dependent upon the METH-induced release of DA. Specifically, the repeated administration of METH (4 or $8 \mathrm{mg} / \mathrm{kg}$ ) administered subcutaneously at two-hour intervals to $\mathrm{BALB} / \mathrm{c}$ mice produced acute behavioral changes following each injection. In particular, the first and second injection of $8 \mathrm{mg} / \mathrm{kg}$ produced intense SIB along with hyperthemia, salivation, and a dramatic increase in striatal 3-methoxytyramine levels. Likewise, SIB following $4 \mathrm{mg} / \mathrm{kg}$ dose of METH was observed after the second and third injections of the drug; that is, compared with the higher dose, the occurrence of these behaviors was shifted from the first injection of the drug. This shift in the occurrence of these behaviors exactly reflected a shift in the amount of available DA for release. That is, over the repeated injections of $\mathrm{METH}$, the amount of DA available for release accurately predicted the occurrence of SIB. Furthermore, these two measures, taken together, accurately reflected the long-lasting depletion of DA induced by the METH.

Other models of SIB also point to involvement of brain DA. Acute bilateral injection of AMPH $(20 \mu \mathrm{g}$ $/ 0.5 \mu \mathrm{l}$ per side) into the vetrolateral striatum was shown to produce licking, self-biting, and repetitive paw-tomouth movements (138), although intense SIB was not reported. In contrast, Mueller et al. (139) reported that chronic administration of low doses of AMPH or caffeine did lead to SIB as did the subcutaneous implantation of silicone pellets containing AMPH (43 \pm $3.6 \mathrm{mg}$ ). Furthermore, these authors found that after removing the pellets, $3 \mathrm{mg} / \mathrm{kg}$ of $\mathrm{AMPH}$ produced the highest rate of SIB (75\%) without accompanying stereotypy. In addition, Moy et al. (140) reported that neonatal 6-OHDA-lesioned rats show SIB when treated as adults with the mixed $D_{1}$ and $D_{2}$ DA receptor agonist L-dopa. In addition, pretreatment with the selective $\mathrm{D}_{1}$ antagonist cis flupentixol attenuated both the SIB and self-biting in these neonatally lesioned animals. Collectively, these studies lead to a convincing conclusion that dopaminergic activation is, at least in part, responsible for SIB.

These earlier studies stressed the role of dopaminergic involvement in mediating SIBs, and this conclusion is consistent with the dominant animal model using neonatal DA lesions and subsequent administration of DA agonists to adults (131). Of importance, Towle et al. (141) ruled out considering any involvement of central 5-HT in mediating SIB. They had observed that L-dopa did cause these behaviors, while 5-hydroxytryptophan (a 5-HT agonist) did not. When we attempted to repli- cate the rat model in mice, we noted that L-dopa, administered to adult mice previously lesioned with 6-OHDA, did not induce the syndrome. However, it was also noted that L-dopa administered to rats increased both DA and 5-HT activity (142), while it only activated dopaminergic neurons in mice (143). As noted, we had already established that high doses of AMPH which caused both DA and 5-HT release did result in SIB in mice. Therefore, we tentatively concluded that the activation of both transmitter systems was essential for the appearance of SIB in any species. Finally, to test this hypothesis, we attempted to block the behaviors with risperidone. a potent $5-\mathrm{HT}_{2}$ and $\mathrm{D}_{2}$ receptor blocker. The risperidone proved to be potent and efficacious in reducing SIB induced by AMPH. In contrast, haloperidol was completely ineffective in reducing the AMPH-induced SIB except at doses that caused a nonspecific sedation. In conclusion, the AMPHs induce SIB consequent to their ability to release DA and 5-HT. The intensity of the SIB accurately reflects the long-lasting toxicity and, furthermore, the sensitivity of this behavior to antagonism by risperidone may have importance for the pharmacotherapy of autism and related disease states where these behaviors are prevalent.

\section{b. Hyperthermia}

The acute administration of METH also induces a significant hyperthermia. It has been speculated that this hyperthermia may be related to the METH-induced neurotoxicity. For example, the neurotoxicity is significantly attenuated in lower environmental temperatures of $4^{\circ} \mathrm{C}$. From these results, it appears that ambient temperature plays an important role in the magnitude of the neurotoxicity $(144-146)$. Bowyer et al. (147) further reported the relationship between the hyperthermia and induction of interleukin (IL)-1. Pretreatment with an antagonist of IL-1 decreased the hyperthermia and mortality associated with METH-induced neurotoxicity. In contrast, IL- $\beta$ mRNA in the hypothalamus was found to be increased by METH-treatment (148). Thus, at first it might appear that hyperthermia may be causally linked with METH-induced neurotoxicity. However, there are some reports that atteuation of METH-induced hyperthermia does not completely protect subjects against the METH-induced neuronal damage. Therefore, METH-induced hyperthermia may be a factor enhancing METH-induced neurotoxicity, but is not a necessary and sufficient condition in METHinduced neurotoxicity.

\section{c. Animal model of Parkinson's disease}

Parkinson's disease is a neurodegenerative disorder with unknown etiology but a strikingly clear neuro- 
pathology consisting of the progressive loss of substantia nigra neurons and a concomitant bleaching of this pigmented nucleus. The loss of these neurons is accompanied by a depletion of striatal DA, a decrease in tyrosine hydroxylase activity, a loss of DA transport pumps, a compensatory increase in DA turnover and postsynaptic receptor proliferation. In addition, Lewy bodies appear in regions experiencing the neuronal loss. The behavioral symptoms of Parkinson's disease include a resting tremor, muscular rigidity, and bradykinesia. Secondary symptoms include difficulties in maintaining posture and gait, difficulties in speaking and swallowing, and eventual compromised respiratory function. The symptoms of Parkinson's disease are first manifest about he age of 60 at a time when $80 \%$ of the dopaminergic projections have already been lost and there is a slight bias in sex with males showing an increased risk for the disease.

The AMPHs present an opportunity for modeling this disease in that the neuropathology does overlap in terms of DA depletion, decreased tyrosine hydroxylase activity, loss of DA uptake sites, the age-dependent increase in sensitivity to the drug, the loss of cell bodies in the substantia nigra, and the increased sensitivity of males as compared to females. The model diverges from the disease in that there are no Lewy bodies present. As noted, the etiology of Parkinson's disease remains elusive, although it is clear that there is not a strong genetic basis. Thus, environmental factors have been seriously considered as causing the neuronal damage. Some have even speculated that humans who abuse AMPHs may have an increased risk for the disease later in life (149).

While receiving the high dose repeated administration of METH, the animals initially exhibit hyperexcitability, with much pacing, checking, sniffing, and exploration and almost zero food intake. The animals never appear to be sleeping. As the regimen continues, these behaviors become increasingly repetitive often with a heightened amount of SIB to a point of ulceration of the skin. Eventually, there appears to be a transition period where the animal, appears exhausted and weakened. At this point there is some intake of preferred diets and the animal does appear to doze off. When the regimen is completed, the animal enters a "depression phase" characterized by a gradual increase in food intake and four to five days of sleeping or resting with hypoactivity. Finally, the animals enter a period of voracious eating and within 2 weeks it is difficult to distinguish experimentally-treated from control subjects. However, through the use of operant behavior techniques, it has been possible to differentiate these experimental animals from the controls. Preliminary evidence indicates that the behavioral alterations are permanent and correlate with neurochemical damage.

In the initial studies, rhesus monkeys were trained on a differential reinforement of low rates (DRL) schedule. When responding was stable, an acute dose-response curve of METH determined that about $1.0 \mathrm{mg} / \mathrm{kg}$ was sufficient to suppress responding for the session. Thereafter, monkeys underwent the repeated administration regimen and were allowed to recover for about 2 months. When the dose-response curve was re-determined, it was observed that there was a substantial tolerance to the disruptive effects of the METH (22, 150). This tolerance is a behavioral pharmacology demonstration of the underlying depletion of DA and suggest that this permanent behavioral alteration is a result of the METH-induced damage.

In rats, the investigation of behavioral consequences of the neuronal damage has been pursued along several lines. The acute induction of stereotypic behavior and of anorexia was not altered by the METH treatment. However, the development of tolerance to the anorexic effects of METH was attenuated in DA depleted rats (27). Measures of activity in a stabilimeter revealed that experimentally depleted rats had a significantly blunted response to the activity enhancing effects of METH and apomorphine and showed a supersensitive response to the activity decreasing effects of haloperidol. Richards etal. (151) showed that rats treated with METH exhibited a long-lasting decrease in a reaction time task, where a response was cued by a stimulus light; fast reaction times were reinforced by access to water. The METH-treated rats showed deficits that would be akin to Parkinson's akinesia.

Finally, the classic strategy to model Parkinson's disease in rodents is to observe a deficit in active avoidance behavior. DA depletions cause a characteristic decrease in the number of avoidance responses without a loss of the escape response. The replacement of lost DA by L-dopa results in a reinstatement of the avoidance behavior $(152,153)$. Rats treated with high doses of METH show a similar reduction in avoidance responding and this was accompanied by an increase in the number of footslips in a balance beam task (154). Finally, in a similar study, the sensitivity of the avoidance response in revealing underlying depletions of DA was demonstrated. AMPH-treated rats with only a $50 \%$ depletion of striatal DA exhibited a significant reduction in the acquisition of a one-way avoidance response. This deficit in their ability to respond to a conditioned stimulus to avoid an impending shock exemplifies the akinetic behavior of the Parkinson's patient. In addition, and again akin to Parkinson's patients, these subjects exhibited a supersensitivity to 
haloperidol.

Thus, there are substantial behavioral deficits following the administration of high doses of the AMPHs. Initially, these are manifest as SIBs caused by the simultaneous release of DA and 5-HT. The SIBs accurately reflect the monoamine release and, perhaps more importantly, reflect the long-lasting toxicity caused by the AMPHs. These SIBs caused by the AMPHs appear to be a useful model of the appearance of these symptoms in patients with autism and related disorders.

Also appearing acutely following AMPH administration is a hyperthermic response. The increased body temperature helps predict later toxicity, but itself is not involved in a causal manner nor is a requisite condition. Finally, the DA depletion caused by the AMPHs, although never as intense as that found in Parkinson's disease, does seem to represent an excellent model for this degenerative disease. Most importantly, subjects with even mild depletions of striatal DA do exhibit deficits in their ability to engage in conditioned avoidance responding and they do exhibit an enhanced sensitivity to dopaminergic antagonists and a tolerance to indirect-acting dopaminergic agonists. The predictive validity of the AMPH models of autism and Parkinson's disease has already been demonstrated. What remains is to use this model to continue to improve pharmacotherapy of these symptoms as well as to gain insight into the etiology of these disease states.

\section{References}

1 Cadet JL, Brannock C. Free radicals and the pathobiology of brain dopamine systems. Neurochem Int. 1998;32:117-131.

2 Frost DO, Cadet JL. Effects of METH-induced neurotoxicity on the development of neural circuitry: a hypothesis. Brain Res Brain Res Rev. 2000;34:103-118.

3 Kita T, Nakashima T. A recent trend in METH-induced neurotoxicty. Nihon Shinkei Seishin Yakurigaku Zasshi. 2002;22:3547. article in Japanese.

4 Gerlach M, Reiderer P. Animal models of Parkinson's disease: an empirical comparison with the phenomenology of the disease in man. J Neural Trans. 1996;103:987-1041.

5 Asanuma M, Hayashi T, Ordonez SV, Ogawa N, Cadet JL. Direct interactions of METH with the nucleus. Mol Brain Res. 2000;80:237-243.

6 Weiss B, Laties VG. Drug effects on the temporal patterning of behavior. Fed Proc. 1964;23:801-807.

7 Schuster CR, Dockens WS, Woods JH. Behavioral variables affecting the development of amphetamine tolerance. Psychopharmacology (Berl). 1966;9:170-182.

8 Segal DS, Mandell AJ. Long-term administration of $d$-amphetamine: progressive augmentation of motor activity and stereotypy. Pharmacol Biochem Behav. 1974;2:249-255.

9 Campbell JC, Seiden LS. Performance influence on the development of tolerance to amphetamine. Pharmacol Biochem Behav.
1973;1:703-708.

10 Kalant OJ. The amphetamines: toxicity and addiction. Toronto: Univ of Toronto Press; 1973.

11 Cook JD, Schanberg SM. Effect of METH on NE metabolism in various regions of brain. J Pharmacol Exp Ther. 1975;195:8793.

12 Heikkila RE, Orlansky H, Mytilineou C, Cohen G. Amphetamine: evaluation of $d$ - and $l$-isomers as releasing agents and uptake inhibitors for ${ }^{3} \mathrm{H}$-dopamine and ${ }^{3} \mathrm{H}-\mathrm{NE}$ in slices of rat neostriatum and cerebral cortex. J Pharmacol Exp Ther. 1977; 194:47-56.

13 Ross SB. Antagonism by methylphenidate of the stereotyped behaviour produced by $(+)$ amphetamine in reserpinized rats. J Pharm Pharmacol. 1978;30:253-254.

14 Lewander T. On the presence of $p$-hydroxynorephedrine in the rat brain and heart in relation to changes in catecholamine levels after administration of amphetamine. Acta Pharmacol Toxicol. 1971;29:33-48.

15 Breese GR, Cooper BR, Mueller RA. Evidence for involvement of 5-hydroxytryptamine in the actions of amphetamine. Br J Pharmacol. 1974;52:307-314.

16 Kuczenski R. Effects of para-chlorophenylalanine on amphetamine- and haloperidol-induced changes in striatal dopamine turnover. Brain Res. 1978;164:217-225.

17 Howlett DR, Nahorski SR. Acute and chronic treatments modulate striatal dopamine binding sites. Brain Res. 1979;161:173178.

18 Reiseine TD, U'Prichard DC, Wiech NL, Ursillo RC, Yamamura HI. Effects of combined administration of amphetamine and iprindole on brain adrenergic receptors. Brain Res. 1980;188:587-592.

19 Bailey RC, Jackson DM. A pharmacological study of changes in the central nervous system receptor responsiveness after long-term dexamphetamine and apomorphine administration. Psychopharmacology (Berl). 1978;56:317-326.

20 Klawans HL, Margolin DI. Amphetamine-induced dopaminergic hypersensitivity in guinea pigs. Arch Gen Psychiatry. 1975;32: 725-732.

21 Jenner P, Pycock C, Marsden CD. The effect of chronic administration and withdrawal of amphetamine on cerebral dopamine receptor sensitivity. Psychopharmacology (Berl). 1978;58:131136.

22 Fischman MW, Schuster CR. Tolerance development to chronic METH intoxication in the rhesus monkey. Pharmacol Biochem Behav. 1974;2:503-508.

23 Seiden LS, Fischman MW, Schuster CR. Long-term METH induced changes in brain catecholamines in tolerant rhesus monkeys. Drug Alcohol Depend. 1975/1976;1:215-219.

24 Caldwell J, Dring LG, Williams RT. Metabolism of $\mathrm{C}^{14} \mathrm{METH}$ in man, the guinea pig and the rat. Biochem J. 1972;129:11-22.

25 Wagner GC, Seiden LS, Schuster CR. METH-induced changes in brain catecholamines in rats and guinea pigs. Drug Alcohol Depend. 1979;4:435-438.

26 Wagner GC, Ricaurte GA, Seiden LS, Schuster CR, Miller RJ, Westley J. Long-lasting depletions of striatal dopamine and loss of dopamine uptake sites following repeated administration of METH. Brain Res. 1980;181:151-160.

27 Bittner SE, Wagner GC, Aigner TG, Seiden LS. Effects of a high-dose treatment of METH on caudate dopamine and anorexia in rats. Pharmacol Biochem Behav. 1981;14:481-486. 
28 Kramer JC, Fischman VS, Littlefield DC. Amphetamine abuse. JAMA. 1967;201:305-310.

29 Melega WP, Raleigh MJ, Stout DB, Lacan G, Huang S-C, Phelps ME. Recovery of striatal dopamine function after acute amphetamine-and METH-induced neurotoxicity in the vervet monkey. Brain Res. 1997;766:113-120.

30 Harvey DC, Lacan G, Tanious SP, Melega WP. Recovery from METH induced long-term nigrostriatal dopaminergic deficits without substantia nigra cell loss. Brain Res. 2000;871:259-270.

31 Wilson JM, Kalasinsky KS, Levey AI, et al. Striatal dopamine nerve terminal markers in human, chronic METH users. Nature Med. 1996;2:699-703.

32 McCann UD, Wong DF, Yokoi F, Villemagne V, Dannals RF, Ricaurte GA. Reduced striatal dopamine transporter density in abstinent METH and methcathinone users: evidence from positron emission tomography studies with $\left[{ }^{11} \mathrm{C}\right] \mathrm{WIN}-35,428$. J Neurosci. 1998;18:8417-8422.

33 Volkow ND, Chang L, Wang GJ, et al. Association of dopamine transporter reduction with psychomotor impairment in METH abusers. Am J Psychiatry. 2001;158:377-382.

34 Gibb JW, Kogan FJ. Influence of dopamine synthesis on METHinduced changes in striatal and adrenal tyrosine hydroxylase activity. Naunyn Schmiedebergs Arch Pharmacol. 1979;310: 185-187.

35 Wagner GC, Ricaurte GA, Johanson CE, Schuster CR, Seiden LS. Amphetamine induces depletion of dopamine and loss of dopamine uptake sites in caudate. Neurology. 1980;30:547-550.

36 Steranka LR, Sanders-Bush E. Long-term effects of continuous exposure to amphetamine on brain dopamine concentration and synaptosomal uptake in mice. Eur J Pharmacol. 1980;65:439443.

37 Fuller RW, Hemrick-Luecke S. Long-lasting depletion of striatal dopamine by a single injection of amphetamine in iprindoletreated rats. Science. 1980;209:305-307.

38 Trulson ME, Jacobs BL. Chronic amphetamine administration to cats: behavioral and neurochemical evidence for decreased central serotonergic function. J Pharmacol Exp Ther. 1979;211: 375-384.

39 Trulson ME, Jacobs BL. Chronic amphetamine administration decreases brain tryptophan hydroxylase activity in cats. Life Sci. 1980;26:329-335.

40 Ricaurte GA, Schuster CR, Seiden LS. Long-term effects of repeated methylamphetamine administration on dopamine and 5-HT neurons in the rat brain: a regional study. Brain Res. 1980;193:153-163.

41 Friedman SD, Castaneda E, Hodge GK. Long-term monoamine depletion, differential recovery, and subtle behavioral impairment following METH-induced neurotoxicity. Pharmacol Biochem Behav. 1998;61:35-55.

42 Nelson MM, Forfar JO. Association between drugs administered during pregnancy and congenital abnormalities of the fetus. Br Med J. 1971;1:523-527.

43 Nora JJ, McNamara DG, Fraser FC. Dexamphetamine sulphate and human malformation. Lancet. 1967;1:570-571.

44 Nasello AG, Ramirez OA. Brain catecholamine metabolism in offspring of amphetamine treated rats. Pharmacol Biochem Behav. 1978;9:17-20

45 Bell RW, Drucker RR, Woodruff AB. The effects of prenatal injections of adrenalin chloride and d-amphetamine sulfate on subsequent emotionality and ulcer proneness of offspring.
Psychon Sci. 1965;2:269-270.

46 Clark CV, Gorman D, Vernodakis A. Effects of prenatal administration of psychotropic drugs on behavior ofd developing rats. Dev Psychobiol. 1970;2:225-235.

47 Tonge S. Permanent alterations in catecholamine concentrations in discrete areas of brain in the offspring of rats treated with methylamphetamine and chlorpromazine. Br J Pharmacol. 1973; 47:425-427.

48 Middaugh LD, Blackwell LA, Santos CA, Zemp JW. Effects of d-amphetamine sulfate given to pregnant mice on activity and on catecholamines in the brains of offspring. Dev Psychobiol. 1974;7:429-438.

49 Hitzemann BA, Hitzemann RJ, Brase DA, Loh HH. Influence of prenatal d-amphetamine administration on development and behavior of rats. Life Sci. 1976;18:605-612.

50 Wagner GC, Schuster CR, Seiden LS. Neurochemical consequences following administration of CNS stimulants to the neonatal rat. Pharmacol Biochem Behav. 1981;14:117-119.

51 Lal H, Sourkes TL. Ontogeny of stereotyped behavior induced by apomorphine and amphetamine in the rat. Arch Int Pharmacodyn Ther. 1973;202:171-182.

52 Lytle LD, Keil FC. Brain and peripheral monoamines: possible role in the ontogenesis of normal and drug-induced responses in the immature mammal. In: Fuxe K, Olsen L, Zotterman Y, editors. Dynamics of degeneration and growth. New York: Pergamon; 1974. p. 575-592.

53 Wagner GC, Lucot JB, Schuster CR, Seiden LS. The ontogeny of aggregation enhanced toxicity. Psychopharmacology (Berl). 1981;75:92-93.

54 Levine MS, Hull CD, Garcia-Rill E, Erinoff L, Bchwald NA, Heller A. Long-lasting decreases in spontaneous firing of caudate neurons induced by amphetamine in cats. Brain Res. 1980;194:263-268.

55 Vorhees CV, Pu C. Ontogeny of METH-induced neurotoxicity in the rat model. NIDA Res Monogr. 1995;158:149-171.

56 Wallace TL, Gudelsky GA, Vorhees CV. Neurotoxic regimen of METH produces evidence of behavioral sensitization in the rat. Synapse. 2001;39:1-7.

57 Wagner GC, Walsh SW. Evaluation of the effects of inhibition of monoamine oxidase and senescence on METH induced neuronal damage. Int J Dev Neurosci. 1991;9:171-174.

58 Mahy N, Andres N, Andrade C, Saura J. Age-related changes of MAO-A and -B distribution in human and mouse brain. Neurobiology. 2000;8:47-54.

59 Wagner GC, Tekirian TL, Cheo CT. Sexual differences in sensitivity to METH toxicity. J Neural Transm. 1993;93:67-70.

$60 \mathrm{Yu} \mathrm{L}$, Liao P-C. Sexual differences and estrous cycle in METHinduced dopamine and 5-HT depletions in the striatum of mice. J Neural Transm. 2000;107:419-427.

$61 \mathrm{Yu}$ L, Wagner GC. Influence of gonadal hormones on sexual differences in sensitivity to METH-induced neurotoxicity. J Neural Transm. 1994;8:215-221.

62 Fukumura M, Cappon GD, Broening HW, Vorhees CV. METHinduced dopamine and 5-HT reductions in neostriatum are not gender specific in rats with comparable hyperthermic effects. Neurotoxicol Teratol. 1998;20:441-448.

63 Kogan FJ, Nichols WK, Gibb JW. Influence of METH on nigral and striatal tyrosine hydroxylase activity and on striatal dopamine levels. Eur J Pharmacol. 1976;36:363-371.

64 Ellison G, Eison MS, Huberman HS, Daniel F. Long-term 
changes in dopaminergic innervation of caudate nucleus after continuous amphetamine administration. Science. 1978;201: 276-278.

65 Hotchkiss AJ, Gibb JW. Long-term effects of multiple doses of METH on tryptophan hydroxylase and tyrosine hydroxylase activity in rat brain. J Pharmacol Exp Ther. 1980;214:257-262.

66 Bower F, Frame LT, Clausing P, et al. Long-term effects of amphetamine neurotoxicity on tyrosine hydroxylase mRNA and protein in aged rats. J Pharmacol Exp Ther. 1998;286:10741085.

67 Hotchkiss AJ, Morgan ME, Gibb JW. The long-term effects of multiple doses of METH on neostriatal tryptophan hydroxylase, tyrosine hydroxylase, choline acetyltransferase and glutamate decarboxylase activities. Life Sci. 1979;25:1373-1378.

68 Fukumura M, Cappon GD, Pu C, Broening HW, Vorhees CV. A single dose model of METH-induced neurotoxicity in rats: effects on neostriatal monoamines and glial fibrillary acidic protein. Brain Res. 1998;806:1-7.

69 Ricaurte GA, Schuster CR, Seiden LS. Increased dopamine metabolism in the rat neostriatum after toxic doses of $d$-methylamphetamine. Neuropharmacology. 1983;22:1383-1388.

70 Cass WA, Manning MW. Recovery of presynaptic dopaminergic functioning in rats treated with neurotoxic doses of METH. J Neurosci. 1999;19:7653-7660.

71 McCabe RT, Hanson GR, Dawson TM, Wamsley JK, Gibb JW. METH-induced reduction in $\mathrm{D}_{1}$ and $\mathrm{D}_{2}$ dopamine receptors as evidenced by autoradiography comparison with tyrosine hydroxylase activity. Neuroscience. 1987;23:253-261.

72 Fields JZ, Wichlinski L, Drucker GE, Engh K, Gordon JH. Long-lasting dopamine receptor up-regulation in amphetaminetreated rats following amphetamine neurotoxicity. Pharmacol Biochem Behav. 1991;40:881-886.

73 Morgan ME, Gibb JW. Short-term and long-term effects of METH on biogenic amine metabolism in extra-striatal dopaminergic nuclei. Neuropharmacology. 1980;19:989-995.

74 Marshall JF, Navarrete RJ. Contrasting tissue factors predict heterogenous striatal dopamine neurotoxicity after MPTP or METH treatment. Brain Res. 1990;534:348-351.

75 Eisch A, Gaffney M, Weihmuller FB, O’Dell SJ, Marshall JF. Striatal subregions are differentially vulnerable to the neurotoxic effects of METH. Brain Res. 1992;598:321-326.

76 Miyakawa T, Sumiyoshi S, Deshimaru M, Murayama E, Tatetsu E. Electron microscopic studies concerning the structural mechanism of the development of mental disturbance in experimental chronic METH poisoning. Acta Neuropathol. 1969;14:215-225.

77 Lorez H. Fluorescence histochemistry indicates damage of striatal dopamine nerve terminals in rats after multiple doses of METH. Life Sci. 1981;28:911-916.

78 Jonsson G, Nwanze E. Selective (+)-amphetamine neurotoxicity on striatal dopamine nerve terminals in the mouse. $\mathrm{Br} \mathrm{J}$ Pharmacol. 1982;77:335-345.

79 Ricaurte GA, Guillery RW, Seiden LS, Schuster CR, Moore RY. Dopamine nerve terminal degeneration produced by high doses of methylamphetamine in rat brain. Brain Res. 1982;235:92103.

80 Hess A, Desiderio C, MCAuliffe WG. Acute neuropathological changes in the caudate nucleus caused by MPTP and METH: immunohistochemical studies. J Neurocytol. 1990;19:338-342.

81 Eisch A, Schmued L, Marshall JF. Characterizing cortical neuron injury with fluoro-jade labeling after a neurotoxic regimen of METH. Synapse. 1998;30:329-333.

82 Schmued LC, Bowyer JF. METH exposure can produce neuronal degeneration in mouse hippocampal remnants. Brain Res. 1997;759:135-140.

83 Sonsalla PK, Jochnowitz ND, Zeevalk GD, Oostveen JA, Hall ED. Treatment of mice with METH produces cell loss in the substantia nigra. Brain Res. 1996;738:172-175.

84 Marek GJ, Vosmer G, Seiden LS. Dopamine uptake inhibitors block long-term neurotoxic effects of METH upon dopamine neurons. Brain Res. 1990;513:274-279.

85 Wagner GC, Preston KL, Ricaurte GA, Schuster CR, Seiden LS. Neurochemical similarities of cathinone and amphetamine. Drug Alcohol Depend. 1982;9:279-284.

86 Ryan LJ, Martone ME, Linder JC, Groves PM. Cocaine, in contrast to $d$-amphetamine, does not cause axonal terminal degeneration in neostriatum and agranular frontal cortex of Long-Evans rats. Life Sci. 1988;43:1403-1409.

87 Wagner GC, Gardner J, Tsigas DJ, Masters DB. Tolerance following the repeated administration of high doses of phencyclidine: no relation to central catecholamine depletion. Drug Alcohol Depend. 1984;13:225-234.

88 Wagner GC, Jarvis MF. Evaluation of the pharmacological similarities between phenylpropanolamine and amphetamine: effects on schedule-controlled behavior. Synapse. 1990;6:101105.

89 Harvey JA, McMaster SE, Fuller RW. Comparison between the neurotoxic and 5-HT-depleting effects of various halogenated derivatives of amphetamine in the rat. J Pharmacol Exp Ther. 1977;202:581-589.

90 Ricaurte GA, Bryan G, Strauss L, Seiden LS, Schuster CR. Hallucinogenic amphetamine selectively destroys brain serotonin nerve terminals. Science. 1985;229:986-988.

91 Axt KJ, Commins DL, Vosmer G, Seiden LS. $\alpha$-Methyl- $p$ tyrosine pretreatment partially prevents METH-induced endogenous neurotoxin formation. Brain Res. 1990;515:269-276.

92 Wagner GC, Lucot JB, Schuster CR, Seiden LS. Alpha-methyltyrosine attenuates and reserpine increases METH-induced neuronal changes. Brain Res. 1983;270:285-288.

93 Schmidt CJ. L-Dopa potentiates the neurotoxicity of some amphetamine analogues. Ann NY Acad Sci. 1992;648:343-344.

94 Seiden LS, Vosmer G. Formation of 6-hydroxydopamine in caudate nucleus of the rat brain after a single large dose of methylamphetamine. Pharmacol Biochem Behav. 1984;21:2931.

95 Marek GJ, Vosmer G, Seiden LS. Dopamine uptake inhibitors block long-term neurotoxic effects of METH upon dopaminergic neurons. Brain Res. 1990;513:274-279.

96 Gibb JW, Johnson M, Hanson GR. Neurochemical basis of neurotoxicity. Neurotoxicology. 1990;11:317-321.

97 Kita T, Wagner GC, Philbert MA, King LA, Lowndes HE. Effects of pargyline and pyrogallol on the METH-induced dopamine depletion. Mol Chem Neuropathol. 1995;24:31-41.

98 Wagner GC, Carelli RM, Jarvis MF. Ascorbic acid reduces the dopamine depletion induced by METH and the 1-methyl-4phenyl pyridinium ion. Neuropharmacology. 1986;25:559-561.

99 De Vito MJ, Wagner GC. METH-induced neuronal damage: a possible role for free radicals. Neuropharmacology. 1989;28: $1145-1150$.

100 Cadet JL, Sheng P, Ali S, Rothman R, Carlson E, Epstein C. Attenuation of METH-induced neurotoxicity in copper/zinc 
superoxide dismutase transgenic mice. J Neurochem. 1994;62: 380-383.

101 Hirata H, Ladenheim B, Carlson E, Epstein C, Cadet JL. Autoradiographic evidence for $\mathrm{METH}$-induced striatal dopaminergic loss in mouse brain: attenuation in $\mathrm{CuZn}$-superoxide dismutase transgenic mice. Brain Res. 1996;714:95-103.

102 Giovanni A, Liang LP, Hastings TG, Zigmond MJ. Estimating hydroxyl radical content in rat brain using systemic and intraventricular salicylate: impact of METH. J Neurochem. 1995;64: $1819-1825$

103 Kita T, Takahashi M, Kubo K, Wagner GC, Nakashima T. Hydroxyl radical formation following METH administration to rats. Pharmacol Toxicol. 1999;85:133-137.

104 Cubells JF, Rayport S, Rajendran G, Sulzer D. METH neurotoxicity involves vacuolation of endocytic organelles and dopamine-dependent intracellular oxidative stress. J Neurosci. 1994;14:2260-2271.

105 Fumagalli F, Gainetdinov RR, Wang YM, Valenzano KJ, Miller $\mathrm{GW}$, Caron MG. Increased METH neurotoxicity in heterozygous vesicular monoamine transporter 2 knock-out mice. J Neurosci. 1999;19:2424-2431.

106 Carlsson M, Carlsson A. Interactions between glutamatergic and monoaminergic systems within the basal ganglia-implications for schizophrenia and Parkinson's disease. Trends Neurosci. 1990;13:272-276.

107 Sonsalla PK, Nicklas WJ, Heikkila RE. Role for excitatory amino acids in METH-induced nigrostriatal dopaminergic toxicity. Science. 1989;243:398-400.

108 Nash JF, Yamamoto BK. METH neurotoxicity and striatal glutamate release: comparison to 3,4-methylenedioxy-METH. Brain Res. 1992;581:237-243.

109 Abekawa T, Ohmori T, Koyama T. Effects of repeated administration of a high dose of METH on dopamine and glutamate release in rat striatum and nucleus accumbens. Brain Res. 1994;643:276-281.

110 Stephans SE, Yamamoto BK. METH-induced neurotoxicity: roles for glutamate and dopamine efflux. Synapse. 1994;17:203209.

111 Itzhak Y, Gandia C, Huang PL, Ali SF. Resistance of neuronal nitric oxide synthase-deficient mice to METH-induced dopaminergic neurotoxicity. J Pharmacol Exp Ther. 1998;284:10401047

112 Garthwaite J. Glutamate, nitric oxide, and cell-cell signaling in the nervous system. Trends Neurosci. 1991;14:60-67.

113 Snyder SH. Nitric oxide: first in a new class of neurotrasmitters. Science. 1992;257:494-496.

114 Beckman JS, Beckman TW, Chen J, Marshall PM, Freeman BA. Apparent hydroxy radical production by peroxynitrite; Implications for endothelial injury from nitric oxide and superoxide. Proc Natl Acad Sci USA. 1990;87:1621-1624.

115 Pisani A, Calabresi P, Centonze D, Bernardi G. Enhancement of NMDA responses by group-1 metabotropic glutamate receptor activation in striatal neurones. Br J Pharmacol. 1997;120:10071014.

116 Salt TE, Binns KE. Contributions of mGlu1 and mGku5 receptors to intractions with $N$-methyl-D-aspartate receptor-mediated responses and nociceptive sensory responses of rat thalamic neurons. Neuroscience. 2000;100:375-380.

117 Bruno V, Ksiazek I, Battaglia G, et al. Selective blockade of metabotropic glutamate receptor subtype 5 is neuroprotective.
Neuropharmacology. 2000;39:2223-2230.

118 Battaglia G, Fornai F, Busceti CL, et al. Selective blockade of mGlu5 metabotropic glutamate receptors is protective against methamphetamine neurotoxicity. J Neurosci. 2002;22:21352142.

119 Shimazoe T, Doi Y, Arai I, Yoshimatsu A, Fukumoto T, Watanabe S. Both metabotropic glutamate I and II receptors mediate augmentation of dopamine release from the striatum in METH-sesitized rats. Jpn J Pharmacol. 2002;88:85-88.

120 Iwasa M, Maeno Y, Inoue H, Koyama H, Matoba R. Induction of apoptotic cell death in rat thymus and spleen after a bolus injection of METH. Int J Legal Med. 1996;109:23-28.

121 Cadet JL, Ordonez, SV, Ordonez JV. METH induces apoptosis in immortalized neural cells: protection by the proto-oncogene, bcl-2. Synapse. 1997;25:176-184.

122 Stumm G, Schlegel J, Schafer T, et al. Amphetamines induce apoptosis and regulation of bcl-x splice variants in neocortical neurons. FASEB J. 1999;13:1065-1072.

123 Hirata H, Cadet JL. METH-induced 5-HT neurotoxicity is attenuated in p53-knockout mice. Brain Res. 1997;768:345-348.

124 Deng X, Jayanthi S, Ladenheim B, Krasnova IN, Cadet JL. Mice with partial deficiency of c-Jun show attenuation of METHinduced neuronal apoptosis. Mol Pharmacol. 2002;62:993-1000.

125 Luchins DJ. Self-Injurious behavior: Introduction. Prog Neuropsychopharmacol Biol Psychiatry. 1990;14:S63-S64.

126 Anderson LT, Ernst M. Self-injury in Lesch-Nyhan disease. J Autism Dev Dis. 1994;24:67-81.

127 Lesch M, Nyhan WL. A familial disorder of uric acid metabolism and central nervous function. Am J Med. 1964;36:561-570.

128 Oliver C, Murphy GH, Cobett JA. SIB in people with mental handicap: a total population study. J Ment Def Res. 1987;31: 147-162.

129 Sandyk R. Self-mutilation in Tourette's syndrome. J Child Neurol. 1988;3:147-148.

130 Khouzam HR, Donnelly NJ. Remission of self-mutilation in a patient borderline personality during risperidone therapy. J Nervous Ment Dis. 1997;185:348-349.

131 Breese G, Baumeister A, McCown T, et al. Behavioral differences between neonatal and adult 6-hydroxydopamine-treated rats to dopamine agonists: relevance to neurological symptoms in clinical syndromes with reduced brain dopamine. J Pharmacol Exp Ther. 1984;231:343-354

132 Stodgell CJ, Loupe PS, Schroeder SR, Tessel RE. Crosssensitizarion between footshock stress and apomorphine on selfinjurious behavior in rat model of Lesch Nyhan syndrome. Brain Res. 1998;783:10-18.

133 Jinnah HA, Langlais PJ, Friedmann T. Functional analysis of brain dopamine systems in a genetic mouse model of LeschNyhan syndrome. J Pharmacol Exp Ther. 1992;263:596-607.

134 Saito Y, Takashima S. Neurotransmitter changes in the pathophysiology of Lesch-Nyhan syndrome. Brain Dev. 2000;22 Suppl 1:S122-S131.

135 Kita T, Paku S, Takahashi M, Kubo K, Wagner GC, Nakashima T. METH-induced neurotoxicity in BALB/c, DBA $/ 2 \mathrm{~N}$ and C57BL/6N mice. Neuropharmacology. 1998;37:1177-1184.

136 Kita T, Matsunari Y, Saraya T, et al. METH-induced striatal dopamine release, behavior changes and neurotoxicity in BALB/c mice. Int J Dev Neurosci. 2000;18:521-530.

137 Kita T, Shimada K, Mastunari Y, Wagner GC, Kubo K, Nakashima T. METH-induced striatal dopamine neurotoxicity 
and cyclooxygenase-2 protein expression in BALB/c mice. Neuropharmacology. 2000;39:399-406.

138 Dickson PR, Lang CG, Hinton SC, Kelly AE. Oral stereotypy induced by amphetamine microinjection into striatum; an anatomical mapping study. Neuroscience. 1994;61:81-91.

139 Mueller K, Saboda S, Palmour R, Nyhan WL. Self-injurious behavior produced in rats by daily caffeine and continuous amphetamine. Pharmacol Biochem Behav. 1982;17:613-617.

140 Moy SS, Criswell HE, Breese GR. Differential effects of bilateral dopamine depletion in neonatal and adult rats. Neurosci Biobehav Rev. 1997;21:425-435.

141 Towle AC, Criswell HE, Maynard EH, et al. Serotonergic innervation of the rat caudate following a neonatal 6-hydroxydopamine lesion: an anatomical, biochemical and pharmacological study. Pharmacol Biochem Behav. 1989;34:367-374.

142 Biggs CS, Starr CS. Microdialysis study of the effects of the antiparkinsonian drug budipine on L-dopa-induced release of dopamine and 5-hydroxytryptamine by rat substantia nigra and corpus striatum. Synapse. 1999;34:36-46.

143 Myers CS, Witten M, Yu Y, Wagner GC. L-Dopa exacerbates amphetamine-induced dopamine depletion. Mol Chem Neuropath. 1998;33:81-97.

144 Bowyer JF, Tank AW, Newport GD, Slikker W Jr, Ali SF, Holson RR. The influence of environmental temperature on the transient effects of METH on dopamine levels and dopamine release in rat striatum. J Pharmacol Exp Ther. 1992;260:817824.

145 Bowyer JF, Gough B, Slikker W Jr, Lipe GW, Newport GD, Holson RR. Effects of a cold environment or age on METHinduced dopamine release in the caudate putamen of female rats. Pharmacol Biochem Behav. 1993;44:87-98.

146 Ali SF, Newport GD, Holson RR, Slikker W Jr, Bowyer JF. Low environmental temperatures or pharmacologic agents that produce hypothermia decrease METH neurotoxicity in mice. Brain Res. 1994;658:33-38.

147 Bowyer JF, Davies DL, Schmued L, et al. Further studies of the role of hyperthermia in METH neurotoxicity. J Pharmacol Exp Ther. 1994;268:1571-1580.

148 Yamaguchi T, Kuraishi Y, Minami M, Nakai S, Hirai Y, Satoh M. METH-induced expression of interleukin-1 beta mRNA in the rat hypothalamus. Neurosci Lett. 1991;128:90-92.

149 Guilarte TR. Is METH abuse a risk factor in Parkinsonism? Neurotoxicology. 2001;22:725-731.

150 Fischman MW, Schuster CR. Long-term behavioral changes in the rhesus monkey after multiple daily doses of $d$-methylamphetamine. J Pharmacol Exp Ther. 1977;201:593-605.

151 Richards JB, Baggott MJ, Sabol KS, Seiden LS. A high-dose METH regimen results in long-lasting deficits on performance of a reaction time task. Brain Res. 1993;627:254-260.

152 Seiden LS, Carlsson A. Temporary and partial antagonism by L-dopa of reserpine-induced supprerssion of a conditioned avoidance response. Psychopharmacologia (Berl). 1963;4:418423.

153 Seiden LS, Carlsson A. Brain and heart catecholamine levels after L-dopa administration in reserpine-treated mice: correlation with a conditioned avoidance response. Psychopharmacologia (Berl). 1964;5:178-181.

154 Walsh SL, Wagner GC. Motor impairments following METHinduced neurotoxicity in the rat. J Pharmacol Exp Ther. 1992; 263:617-626.

155 Sabol KE, Roach JT, Broom SL, Ferreira C, Preau MM. Longterm effects of a high-dose methamphetamine regimen on subsequent methamphetamine-induced dopamine release in vivo. Brain Res. 2001;892:122-129.

156 Deng X, Wang Y, Chou J, Cadet JL. Methamphetamine causes widespread apoptosis in the mouse brain: evidence from using an improved TUNEL histochemical method. Brain Res Mol Brain Res. 2001;93:64-69.

157 Jayanthi S, Deng X, Bordelon M, McCoy MT, Cadet JL. Methamphetamine causes differential regulation of pro-death and anti-death Bcl-2 genes in the mouse neocortex. FASEB J. 2001;15:1745-1752.

158 Imam SZ, Newport GD, Itzhak Y, et al. Peroxynitrite plays a role in methamphetamine-induced dopaminergic neurotoxicity: evidence from mice lacking neuronal nitric oxide synthase gene or overexpressing copper-zinc superoxide dismutase. J Neurochem. 2001;76:745-749.

159 Thiriet N, Jayanthi S, McCoy M, Ladenheim B, Cadet JL. Methamphetamine increases expression of the apoptotic c-myc and L-myc genes in the mouse brain. Mol Brain Res. 2001; 90:202-204.

160 Deng X, Cadet JL. Methamphetamine-induced apoptosis is attenuated in the striata of copper-zinc superoxide dismutase transgenic mice. Mol Brain Res. 2000;83:121-124.

161 Deng X, Ladenheim B, Tsao LI, Cadet JL. Null mutation of cfos causes exacerbation of methamphetamine-induced neurotoxicity. J Neurosci. 1999;19:10107-10115. 